\title{
Representações Sociais do Meio Ambiente: Implicações em Abordagens de Educação Ambiental sob a Perspectiva Crítica com Alunos da Primeira Etapa do Ensino Fundamental
}

\author{
Social Representations of the Environment: \\ Implications in Environmental Education Approaches under the Critical \\ Perspective with Students in the First Stage of Elementary School
}

\author{
iD Dayvisson Luis Vittorazzi ${ }^{1}$ \\ Daniele da Silva Maia Gouveia' \\ Alcina Maria Testa Braz da Silva²
}

${ }^{1}$ Centro Federal de Educação Tecnológica Celso Suckow da Fonseca (CEFET), Laboratório de Pesquisa em Educação em Ciências e Representações Sociais (EDUCIRS), Rio de Janeiro, RJ, Brasil. Autor correspondente: dlvittorazzi@gmail.com ${ }^{2}$ Centro Federal de Educação Tecnológica Celso Suckow da Fonseca (CEFET), Departamento de Pesquisa e Pós-graduação, Rio de Janeiro, RJ, Brasil.

Resumo: Amparado pelo referencial teórico-metodológico da Teoria das Representações Sociais, com atenção especial a sua abordagem estrutural, o presente trabalho trouxe como objetivo identificar o conteúdo e a organização das representações de Meio Ambiente construídas por um grupo de alunos do $4^{\circ}$ ano do Ensino Fundamental de uma escola municipal no Estado do Espírito Santo. Sinaliza, ainda, sua relevância quando no interesse de aplicação de propostas de trabalho pedagógico sob o foco da Educação Ambiental Crítica. Por meio de técnicas aplicadas à Teoria do Núcleo Central foi possível compreender que a representação dos alunos se ordena em torno de elementos que se relacionam a visões naturalistas, conservacionistas e antropocêntricas-utilitaristas de meio ambiente. As análises permitiram inferir algumas relações dessas representações com estratégias no sentido de promover uma visão articulada de caráter globalizante, onde o meio é integrado pelo ambiente e pela sociedade. Os resultados pretendem contribuir nas discussões acerca dos processos de Educação Ambiental sob a perspectiva Crítica.

Palavras-chave: Representações sociais; Educação ambiental crítica; Ensino fundamental. Meio ambiente e educação.

Abstract: Supported by the theoretical-methodological framework of the Theory of Social Representations, with special attention to its structural approach, this paper aimed to identify the content and organization of the Environmental representations constructed by a group of students in the 4th grade of a municipal Elementary School in the state of Espírito Santo, Brazil. Its relevance should also be noted for the interest in applying pedagogical work proposals under the focus of Critical Environmental Education. With techniques applied to Central Core Theory, it was possible to understand that students' representations are organized around elements that relate to naturalistic, conservationist and anthropocentric-utilitarian views of the environment. The analysis permitted to infer some relations among these representations and strategies in order to promote an articulated vision of globalizing character, where the surroundings are integrated by the environment and society. The results intend to contribute to discussions about the processes of Environmental Education from the Critical perspective.

Keywords: Social representation; Critical environmental education; Elementary school; Environment and education.

Recebido em: 12/09/2019

Aprovado em: 15/07/2020 


\section{Introdução}

Neste trabalho, apresentamos um estudo acerca do conteúdo cognitivo-estrutural de representações sociais (doravante RS) do Meio Ambiente mantidas por um grupo de alunos do $4^{\circ}$ ano do Ensino Fundamental, de uma escola municipal do Estado do Espírito Santo. Objetivamos, por meio das análises, sinalizar a relevância desses estudos na mediação de propostas de trabalho didático sob o foco da Educação Ambiental Crítica nessa etapa de ensino.

O presente estudo surgiu a partir do interesse em refletir sobre o trabalho pedagógico de Educação Ambiental sob a perspectiva crítica. Nesse sentido, entendemos a necessidade de conhecer o conjunto de representações, imagens e concepções que nosso grupo de alunos mantinha acerca do objeto Meio Ambiente, no intuito de compreendermos como o pensar e o agir dos discentes são orientados. O conhecimento das diferentes representações do grupo se caracterizou como uma etapa inicial fundamental para a condução de atividades que permitissem uma reflexão e, até mesmo, uma reestruturação de conhecimentos que pudessem parecer divergentes, ambíguos ou equivocados sobre o tema.

Para Carvalho (2012), organizamos o que nos cerca por meio das visões e dos conceitos que produzimos, no objetivo de tornar o mundo inteligível e habitual. Podemos, por esse ângulo, entender que as imagens que produzimos do ambiente a nossa volta não são como as produzidas pelos retratos objetivos e neutros do mundo natural, mas exprimem as visões de natureza que culminam, de forma expressiva, na formação das representações do meio ambiente compartilhadas em um conjunto social. A questão que se põe, conforme a mesma autora, é "[...] quais expectativas e valores socio-históricos estão contidos nessa construção sobre a natureza?" (CARVALHO, 2012, p. 35).

Para essa demanda, trazemos por princípio que a formação do cidadão ciente de seu papel na sociedade e dos fenômenos que acontecem ao seu redor é tarefa, também, da educação escolar, haja vista as proposições da nova Base Nacional Comum Curricular (BNCC), que trazem como princípio fundamental a formação integral dos educandos, no uso de perspectivas cognitivas e afetivas, contribuindo na construção de cidadãos plenos, autônomos e engajados nas questões contemporâneas (BRASIL, 2018). Esse processo, por tamanha complexidade, deve ser privilegiado ainda na infância, pois é nesta fase que a aprendizagem de conceitos e valores é mais significativa, potencializando suas marcas para as demais fases da vida. Para que esta formação aconteça, no entanto, faz-se necessário que o indivíduo tenha acesso a uma ampla gama de conhecimentos, dentre eles, os científicos, sem descartar as implicações sociais, culturais e ambientais que todo o desenvolvimento científico e tecnológico tem gerado.

Pretendemos, neste texto, sinalizar os principais aspectos que caracterizam a Educação Ambiental Crítica, refletindo acerca do trabalho sob esta perspectiva como possibilidades para uma formação transformadora e emancipatória, trazendo, ainda, a relevância dos estudos de RS no campo educacional. 


\section{Referencial Teórico-Metodológico}

\section{A Educação Ambiental e uma de suas múltiplas orientações: a Educação Ambiental Crítica}

A ação humana no planeta é histórica, porém, podemos dizer que os distúrbios ambientais tornaram-se mais recorrentes dada a Revolução Industrial. Os impactos produzidos pelos processos industriais e suas subsequentes exigências de exploração e consumo dos recursos naturais têm alterado os modos de vida e despertado o interesse mundial para o tema. Partindo das ideias atribuídas ao vocábulo ecologia por Ernst Haeckel, em 1869, é possível sinalizar que inúmeras ações individuais e coletivas, desde então, têm demonstrado preocupação com a relação entre as espécies e seu ambiente.

As publicações de Silent spring (Primavera em silêncio), por Raquel Carson (CARSON, 1962) e The limits to growth (Os limites do crescimento), por Donella H. Meadows (MEADOWS et al., 1972) caracterizam vultosos exemplos. Tais publicações tiveram grande repercussão e, juntamente com outros movimentos ecológicos, caracterizaram as primícias da Educação Ambiental. Esses movimentos ganharam expressividade e cada vez mais adeptos, visto a preocupação social com o futuro da vida e com as necessidades básicas das presentes e das advindas gerações, fornecendo caminhos para diversas ações coletivas mundiais e discussão dos temas ambientais. Para Carvalho (2012, p. 51), a Educação Ambiental pode ser considerada a "[...] herdeira direta do debate ecológico e está entre as alternativas que visam construir novas maneiras de os grupos sociais se relacionarem com o meio ambiente", possibilitando a modificação de valores em busca de uma melhoria de vida para todos de forma igualitária e sustentável.

Para Reigota (1997), a análise das problemáticas ambientais em amplitude mundial se intensificou após a fundação do Clube de Roma, em 1968, e da Conferência de Estocolmo, em 1972. Nesta última, acentuamos deliberações que sinalizavam "[...] para a necessidade de se realizar a educação ambiental tendo em vista a participação dos cidadãos na solução dos problemas ambientais" (REIGOTA, 1997, p. 9). Acrescentamos a estas citações, a Conferência de Belgrado, realizada pela Unesco em 1975, que reuniu especialistas em educação e áreas relacionadas ao meio ambiente com o propósito de discutir objetivos, conteúdos e métodos para a educação ambiental. A conferência culminou na publicação de um documento instrucional, conhecido como a Carta de Belgrado.

Em 1977, na Conferência de Tbilisi, na Geórgia, foram estabelecidos os princípios orientadores da educação ambiental e seu caráter interdisciplinar, critico, ético e transformador foi acentuado. Em 1992 acontece a Conferência sobre o Meio Ambiente e o Desenvolvimento, UNCED, Rio92, decorrendo a criação da Agenda 21 e o Tratado de Educação Ambiental para Sociedades Sustentáveis. Com a Rio92, surge a Carta Brasileira de Educação Ambiental, que, junto ao percurso histórico de consolidação do discurso ambiental, coincidiu na reelaboração dos pressupostos da educação com a intenção de sensibilizar os indivíduos para a questão ambiental (BRASIL, 2020).

No Brasil, a Educação Ambiental é tratada em leis desde 1973, como incumbência da exordial Secretaria Especial do Meio Ambiente, "[...] mas é principalmente nas décadas de 80 e 90, com o avanço da consciência ambiental, que a EA cresce e se torna mais conhecida" (CARVALHO, 2012, p. 52). A Lei 9.795, de 27 de abril de 1999, que dispõe sobre a educação ambiental e institui a Política Nacional de Educação Ambiental, em seu artigo $1^{\circ}$ apresenta que: 
Entende-se por Educação Ambiental os processos por meio dos quais o indivíduo e a coletividade constroem valores sociais, conhecimentos, habilidades, atitudes e competências voltadas para a conservação do meio ambiente, bem de uso comum do povo, essencial à sadia qualidade de vida e a sua sustentabilidade (BRASIL, 1999).

Nos termos da educação escolar, os Parâmetros Curriculares Nacionais (PCN), produzidos em conformidade com a Lei de Diretrizes e Bases da Educação Nacional, trazem os fundamentos pedagógicos e legais das diretrizes para a Educação Básica no cenário nacional. Já neste documento, o tema Meio Ambiente aparece descrito nos denominados Temas Transversais, os quais são indicados a serem discutidos pelas diferentes disciplinas que compõem a grade das séries do Ensino Fundamental (BRASIL, 1998). Em caráter mais hodierno, a Base Nacional Comum Curricular dispõe que

[...] cabe aos sistemas e redes de ensino, assim como às escolas, em suas respectivas esferas de autonomia e competência, incorporar aos currículos e às propostas pedagógicas a abordagem de temas contemporâneos que afetam a vida humana em escala local, regional e global, preferencialmente de forma transversal e integradora (BRASIL, 2018, p. 19).

Esses temas estão ancorados nos desafios do mundo atual, dentre os quais destacase a Educação Ambiental, amparada pela Lei n 9.795/1999, Parecer CNE/CP n 14/2012 e Resolução CNE/CP n 2/2012 (BRASIL, 2012a, 2012b). O trabalho com essas questões caracteriza o interesse de formação integral dos educandos, compreendendo o desenvolvimento de capacidades de interpretar o mundo e perceber suas interações de modo a envolver-se de forma responsável e ética (BRASIL, 2018).

A este contexto destacamos que, sob a denominação de Educação Ambiental, existe uma diversidade de orientações se perpetuando por meio de suas diferentes práticas, metodologias e posturas sócio-políticas, caracterizando-se como Educação Ambiental popular, formal, não-formal, para o desenvolvimento sustentável, dentre outras. No entanto, essa multiplicidade de denominações é quase imperceptível a imperitos. Assim como Schünemann e Rosa (2010), defendemos que a Educação Ambiental deve atuar já nas fases iniciais de formação, em que a criança está envolvida com formas mais lúdicas de ensinar e aprender e, se for sensibilizada desde a infância sobre suas responsabilidades, certamente será um adulto ciente de seu papel, formando sociedades mais justas.

Dentre as muitas práticas, destacamos a Educação Ambiental Crítica, que se apresenta como alternativa a uma educação ambiental hegemônica e que, para alguns autores, como Bomfim e Piccolo (2011), é uma evolução do conceito, e para outros, como Carvalho (2012), é mais uma orientação que contribuirá em um diálogo entre as outras, não sendo possível sintetizar as diferentes concepções de educação ambiental em uma só. Existem ainda os que acreditam ser uma contraposição à Educação Ambiental dita conservadora (GUIMARÃES, 2004). De modo geral, como já nos apresentava Reigota (1997), o princípio da educação ambiental reside em

[...] uma proposta que altera profundamente a educação como a conhecemos, não sendo necessariamente uma prática pedagógica voltada para a transmissão de conhecimentos sobre ecologia. Trata-se de uma educação que visa não só a utilização racional dos recursos naturais (para ficar só nesse exemplo), mas basicamente a participação dos cidadãos nas discussões sobre a questão ambiental (REIGOTA, 1997, p. 10-11). 
Segundo Loureiro et al. (2009), a Educação Ambiental Crítica, transformadora e emancipatória emerge da pedagogia crítica, que tem seu ponto de partida na teoria crítica de interpretação da realidade social, tendo como referencial teórico o pensamento marxista. A educação crítica se fundamenta na liberação dos indivíduos das amarras do sistema por meio de ideais democráticos, propiciando a estes um reconhecimento de seu valor e de seu papel como agentes transformadores da sociedade e de sua própria história.

Na Educação Ambiental Crítica, há uma discussão mais ampla acerca do conteúdo político-ideológico ancorado no teor socioambiental já existente na Educação Ambiental Tradicional. Por meio dela, se repensam as forças do discurso político e ideológico que tanto influenciam nas questões ambientais (BOMFIM; PICCOLO, 2011). Trata das questões ambientais e suas causas mediante um contexto social e histórico. Para Guimarães (2004, p. 35),

Esse processo educativo se dá na adesão ao movimento da realidade socioambiental, numa relação dialética de transformação do indivíduo e da sociedade reciprocamente, o público da Educação Ambiental Crítica é a sociedade constituída por seus atores individuais e coletivos, em todas as faixas etárias.

Sob a perspectiva da transformação social, a Educação Ambiental Crítica nos parece mais problematizadora em seus objetivos, visto que se propõe compreender os problemas socioambientais em sua essência, longe de ensaios reducionistas ou tendenciosos a ideologias dominantes, frequentemente presentes nas práticas tradicionais e mecanizadas realizadas em espaços formais e não-formais, meios comunicativos, campanhas empresariais, dentre outros. A intenção, de modo sumário, é formar sujeitos possuidores de uma ampla visão de mundo para que possam se posicionar com uma tomada de atitude no aspecto ambiental, contribuindo para a construção de uma nova realidade.

\section{A Teoria das Representações Sociais e o campo educacional}

A Teoria das Representações Sociais (TRS) foi formulada pelo psicólogo social Serge Moscovici por meio de seu trabalho de doutoramento intitulado La Psychanalyse, son image et son public, externado em 1961, no qual articulou conceitos da psicologia e da sociologia, renovando a noção de Representações Coletivas proposta por Émile Durkheim. Segundo Duveen (2007), Moscovici buscou a condução de uma ciência "mista", intermediada pelo conceito de representação, e assim retomou os préstimos de Durkheim. Partindo da herança ambígua para a psicologia social da formulação do conceito de representações coletivas por Durkheim, Moscovici sugeriu interesse em enfatizar a "[...] qualidade dinâmica das representações contra o caráter mais fixo, ou estático, que elas tinham na teoria de Durkheim" (DUVEEN, 2007, p. 14), adotando, para tanto, o termo "social".

Em sua pesquisa, investigou como a psicanálise era representada pela sociedade parisiense, com o objetivo de explorar o conjunto de ideias coletivas que possibilitaram a apreensão desse conceito científico por diferentes grupos sociais. Neste contexto, apresentou as RS como fenômenos particulares que compõem o senso comum e criam determinada realidade, circulando como entidades quase tangíveis na comunicação e nas ações dos indivíduos (MOSCOVICl, 2012). Esses fenômenos conduzem a análise dos assuntos cotidianos, originando um tipo de saber prático que tem por finalidade traduzir algo incomum para algo corrente. 
Os mecanismos de produção e reestruturação desses fenômenos se configuram por meio do que Moscovici (2012) denomina de objetivação e ancoragem, processos articulados, porém sem comprometimento de ordenação nem hierarquia, que transformam a informação abstrata em algo existente no mundo físico (objetivação) e ajustam sua singularidade a um contexto já conhecido (ancoragem), que se refletem nas práticas sociais (MOSCOVICl, 2012).

Advinda de uma posição mista no encadeamento de uma série de conceitos sociológicos e psicológicos, a TRS tem sido tratada por diferentes áreas de conhecimento, o que permitiu profusos olhares para suas concepções e fomentou distintas contribuições à teoria. Estas se configuraram como abordagens complementares à TRS, dentre as quais, por interesse do presente trabalho, trataremos com maior amplitude da perspectiva estrutural.

A abordagem estrutural contou com os estudos de Jean-Claude Abric (ABRIC, 1993, 1998), que apuravam as características cognitivo-estruturais de RS e contribuíram na elaboração da Teoria do Núcleo Central (TNC) (SÁ, 1996). Segundo a teoria, "[...] uma representação é composta de um conteúdo e de uma organização ou estrutura, essa última dividida em dois sistemas (núcleo central e elementos periféricos), cada um assegurando diferentes funções" (CAMPOS, 2017, p. 790). Esses elementos estruturais possuem papéis específicos e complementares: um "[...] sistema central (o núcleo central), cuja determinação é essencialmente social, ligada às condições históricas, sociológicas e ideológicas" (ABRIC, 1998 , p. 33), congruente a um conjunto de valores e normas, que atribui significado à RS; e um "[...] sistema periférico, [...] associado às características individuais e ao contexto imediato e contingente, nos quais os indivíduos estão inseridos" (ABRIC, 1998, p. 33).

Essas proposições relativas à estrutura organizacional de uma representação procuraram explicar duas de suas características, notoriamente contraditórias: "[...] as representações sociais são ao mesmo tempo estáveis e móveis, rígidas e flexíveis [...], são consensuais, mas também marcadas por fortes diferenças interindividuais" (ABRIC, 1993, p. 75, tradução nossa).

Baseados nessas proposições, alguns pesquisadores desenvolveram contribuições no planejamento de métodos para o apontamento do conteúdo das RS e sinalização do provável núcleo central (NC). Neste contexto, apresentam-se bastante profícuos os trabalhos de Pierre Vergès (VERGĖS, 1992 apud SÁ, 1996, p. 177). Na promoção de um método de análise, esse autor combinou alguns atributos de memorações produzidas a partir de um termo indutor. Esse conjunto metodológico de trabalho, como destaca Sá (1996, p. 177), por mais objetivo e criterioso que possa parecer, não parece suficiente para dar conta da uma percepção global do fenômeno representacional, porém, sugere que, na sua ausência, "[...] abre-se um perigoso espaço para avaliações meramente impressionistas da importância relativa das diferentes cognições para a organização da representação", sendo sua aplicação necessária aos estágios iniciais de uma abordagem plurimetodológica nos estudos de Representações Sociais.

É possível realçar diversas possibilidades de cooperação entre os estudos de RS e os diferentes campos do saber, porém, como foco do presente trabalho, sublinhamos as que tangem o âmbito educacional. Os empenhos de Alves-Mazzotti (2008), Chaib (2015), Gilly (2002), Ornellas (2009), Silva e Mazzotti (2009), dentre inúmeros outros, revelam que a TRS, juntamente com suas complementações, mostrou ser um instrumento valioso para o estudo de diversas questões relacionadas aos processos educacionais. Nessas articulações, de modo geral, Gilly (2002, p. 232) sinaliza que a noção de RS "[...] orienta a atenção sobre o papel de conjuntos organizados de significações sociais no processo educativo". Assim, pesquisas 
encadeadas à TRS assumem importante relevância, uma vez que fornecem instrumentos que contribuem na apreciação das condutas e comunicações sociais nas diferentes esferas educacionais.

Nesse engendramento, é possível perceber recorrente atenção aos conhecimentos trazidos para as salas de aula, por seus diferentes atores, e amplas discussões são concebidas acerca da sua impressão nos processos de ensino e aprendizagens, visto que aos indivíduos cabe o processamento de cada situação que lhes é apresentada a partir do conjunto de saberes que carrega. Em consequência, nesses processos residiria a reestruturação de conhecimentos mais simples para o alcance de produções mais elaboradas (POZO; CRESPO, 2009).

Para Pozo e Crespo (2009), esses saberes representacionais (prévios ou alternativos) têm gênese nas diferentes interações sociais dos indivíduos e podem se materializar na forma de RS, as quais compreendem adjuntos de crenças, imagens, concepções, que podem originar idealizações, como, por exemplo, de modos de contágio e transmissão de doenças, de mecanismos de interações ambientais e diversos outros conceitos que podem, muitas vezes, ter um significado diferente na linguagem cotidiana e nos esquemas científicos.

Os estudos de RS foram introduzidos no Brasil no início dos anos 1980, fato marcado pelo retorno de profissionais que buscavam aperfeiçoamento na Europa e, desde então, suas potencialidades têm despertado o interesse de pesquisadores (SÁ; ARRUDA, 2000). Acompanhando o cenário de consolidação da teoria no país, surgiram substanciais trabalhos acerca do tema "meio ambiente", impulsionados pela relevância dada ao enunciado em diversas conferências mundiais que discutiam, de modo geral, impactos do desenvolvimento no ambiente (REIGOTA, 1997). Já no final dos anos 1990, Reigota (1997) apresentava os resultados de suas análises sobre o meio ambiente, RS e prática pedagógica, propondo que as RS de um grupo de professores poderiam caracterizar suas práticas docentes relacionadas ao tema. Desde então, seguindo os impulsos para o desenvolvimento de uma Educação Ambiental para a cidadania, o tema tem permeado publicações nas diversas áreas das Ciências Humanas e Naturais, como, a título de exemplo, citamos os esforços de Cavalcanti Neto e Amaral (2011), Fonseca e Oliveira (2011), Nascimento-Schülze (2000), Rosa e Santos (2017), e Sauvé (2003).

No interesse de verificar as contribuições de investigações que tratam de RS para a área de Ensino de Ciências, Vittorazzi (2018), partindo de um levantamento em periódicos nacionais, sinaliza que temas ambientais se caracterizam fortemente como objetos nas referidas pesquisas e destaca que elas

[...] fornecem contribuições para reflexões sobre o papel e a medida que esse tipo de conhecimento deve assumir nos processos de ensino e aprendizagem, o que pode amenizar tensões estabelecidas em sala de aula, principalmente quando relativas a assuntos que passam por um crivo sentimental, cultural ou religioso. Fornecem, também, um carátervaloroso aoconhecimento comumeconcorrem paraumaformação política para o exercício da cidadania, pois consideram elementos sociais, econômicos e culturais na produção desse saber, o qual orienta as ações desses indivíduos nos diversos contextos nos quais estiverem inseridos (VITTORAZZI, 2018, p. 70).

Campos (2017) destaca que um dos desafios atuais para os estudos de RS seria a análise da ancoragem como uma direção para se entender de que modo os sujeitos aliam seus sistemas sociocognitivos ao contexto dos espaços de aprendizagens, sendo necessárias, 
para tanto, investigações que ultrapassem o caráter descritivo das RS e remontem à "[...] compreensão dinâmica dos fatores psicossociais que participam da construção da função social" (LIMA; CAMPOS, 2015 apud CAMPOS, 2017, p. 793) da escola e seus agentes.

Quanto à construção do objeto da presente pesquisa, é necessário considerarmos que os modos de vida têm frequentemente sofrido profundas mudanças, sendo estas produzidas pela ação histórica da humanidade no planeta. Torna-se praticamente impossível manterse alheio a essas ações, visto seu caráter agressivo aos meios necessários ao equilíbrio ambiental e, dessa maneira, nos tempos hodiernos, tratar dessas questões tornou-se altamente considerado como possibilidade de uma Educação Ambiental para a Cidadania. Diante dos fatos, faz-se fundamental, porém, discutir o que é meio ambiente, tratando das relações entre ambiente e sociedade de forma crítica, o que justifica a relevância cultural e espessura social do objeto.

Assim sendo, esses preceitos caracterizam referências teórico-metodológicas coesas com os objetivos propostos no presente trabalho, que pretendem um diagnóstico introdutório do tema meio ambiente para alunos do Ensino Fundamental, permitindo discussões sobre suas implicações em estratégias de abordagem pedagógica de Educação Ambiental. Entendemos, nesse enredo, que as propostas deste estudo se enquadram aos inquéritos psicossociais, usualmente desenvolvidos em pesquisas no campo da Psicologia Social, baseados nas indicações de Jovchelovitch (2004, p. 21), que sugerem que as produções desta área fornecem detalhamentos da zona "nebulosa e híbrida que comporta as relações" entre os sujeitos e seu grupo, o que fornece relevantes contribuições a um diálogo interdisciplinar.

\section{Metodologia da Pesquisa}

A aplicação da Teoria das Representações Sociais (TRS) não está condicionada a nenhum método específico de pesquisa, porém, a literatura especializada orienta o uso de técnicas na coleta dos dados empíricos por meio de inquéritos e evocação livre de palavras quando o interesse do pesquisador se concentrar no trabalho orientado pela abordagem estrutural (SÁ, 1996).

Como mecanismo de coleta de dados, utilizamos um questionário com questões abertas e itens para evocação livre de palavras a partir do termo indutor Meio Ambiente, aplicado a 50 alunos do quarto ano do Ensino Fundamental de uma escola municipal localizada no Estado do Espírito Santo. Para o presente trabalho, tratamos apenas das questões relativas à evocação livre de palavras, uma vez que trazemos atenção às primeiras etapas da abordagem plurimetodológica tratada por Abric: o levantamento do conteúdo da representação e pesquisa da estrutura e do NC (SÁ, 1996).

Os dados levantados por meio dessa técnica foram homogeneizados e organizados em tabelas, sendo processados com auxílio dos softwares Evocation ${ }^{1}$ e Iramuteq $^{2}$ e analisados a partir do método proposto por Pierre Vergès para a identificação dos prováveis elementos estruturais da RS, baseado na abordagem estrutural pretendida pela TNC (SÁ, 1996; VERGÈS, 2001).

\footnotetext{
"Ensemble de programmes permettant l'analyse des evocations", o Evocation é um software elaborado por Pierre Vergès e seus colaboradores, possuindo vários sub-programas que permitem a inserção e o tratamento de dados estatísticos para posterior análise de termos pela verificação das frequências e ordens de sua evocação. 2"Interface de R pour lês analyses multidimensionnelles de texte set de questionnaires", o Iramuteq é um software livre desenvolvido por Pierre Ratinaud, sustentado pelo software $\mathrm{R}$, que permite a realização de análises estatísticas de corpus textuais, incluindo a análise de similitude de termos.
} 
O método de levantamento dos elementos do NC elaborado por Vergès (1992 apud SÁ, 1996, p. 116), relaciona "[...] a frequência de emissão das palavras e/ou expressões com a ordem em que estas são evocadas". Além disso, é possível utilizar a análise das relações estabelecidas entre os elementos da RS como meio de reiterar a composição do núcleo central (SÁ, 1996), sendo possível a criação de categorias no intuito de coletar indicações da organização da representação. Neste estudo, adotamos esses métodos para a sondagem das palavras ou expressões que concorreram, com maior probabilidade, ao sistema central da RS, visto, dessa forma, o caráter prototípico (relativo à evidência) e símile (relativo à conexidade) desses termos.

Por meio da realização da análise prototípica, enumeramos os elementos centrais e periféricos da RS, resultando na produção do Quadrante de Vergès (Figura 1). Neste, com o auxílio do software Evocation, dispomos os termos evocados em quatro quadros, caracterizados pelo cruzamento das frequências e ordem média dessas evocações. No $1^{\circ}$ quadrante, foram alocados os componentes mais frequentes e mais prontamente evocados; no $2^{\circ}$, os elementos com elevada frequência, porém evocações mais tardias do que as do $1^{\circ}$ quadro; no $3^{\circ}$, os que possuíam baixa frequência, porém considerados importantes pelos alunos; e no $4^{\circ}$, os termos com baixa regularidade e evocados por último (SÁ, 1996).

Figura 1 - Quadrante de Vergès

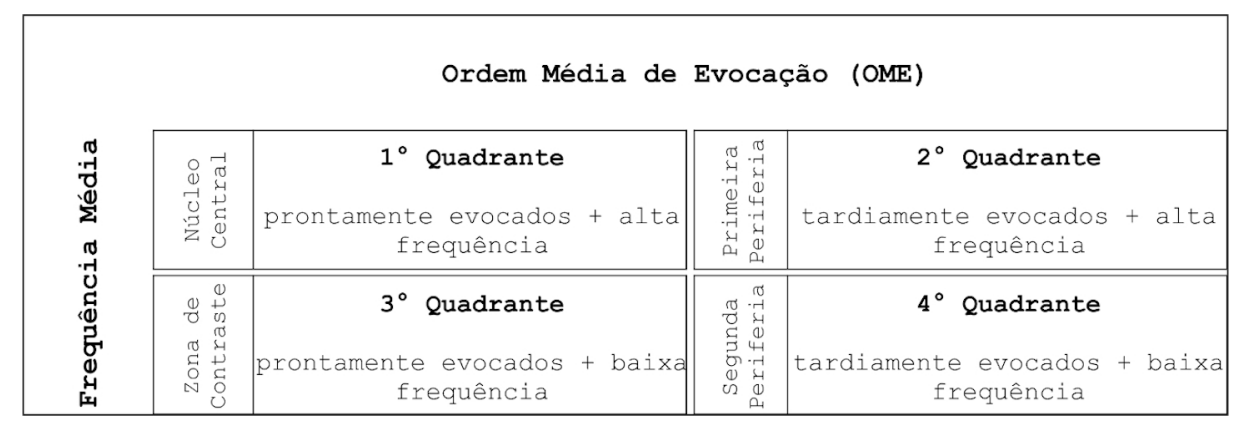

Fonte: adaptado de Sá (1996).

A análise prototípica foi "[...] complementada pela análise de similitude do termo, confirmando sua centralidade, por um processo de análise de coocorrências que indica a conexidade" (VOGEL, 2016, p. 108). Adotamos, por meio do software Iramuteq, o cálculo dos índices de similitude entre os termos que traziam frequência significativa, resultando em uma "[...] árvore máxima que sintetiza, graficamente, o conjunto das conexões existentes entre tais termos" (VOGEL, 2016, p. 108). De acordo com Sá (1996, p. 126), a análise de similitude foi inaugurada no campo das RS nos anos de 1970 por Claude Flament, com o suporte de outros pesquisadores, tornando-se a "[...] principal técnica de detecção do grau de conexidade dos diversos elementos de uma representação".

Na compreensão da configuração dos elementos e suas correspondentes relações simbólicas, que definem os sistemas central e periférico da RS, aplicamos técnicas da Análise de Conteúdo (BARDIN, 1977) aos termos e justificativas considerados neste estudo, privilegiando a Análise Categorial Temática. Nesse sentido, as evocações produzidas pelos alunos foram agrupadas em unidades (categorias) de registro segundo seu contexto de significação (FRANCO, 2005), conforme o Quadro 1. A análise dessas categorias observou a base de discussões presentes em estudos precedentes desenvolvidos por Abílio et al. (2005), Carvalho (2012), Fonseca e Oliveira (2011), Nascimento-Schülze (2000), e Reigota (1997). 
Quadro 1 - Categorias elaboradas para os termos da Representação Social do Meio Ambiente

\begin{tabular}{|l|l|}
\hline \multicolumn{1}{|c|}{ Unidades de Registro } & \multicolumn{1}{c|}{ Unidades de Significação } \\
\hline $\begin{array}{l}\text { Espaço, elementos bióticos e } \\
\text { abióticos }\end{array}$ & $\begin{array}{l}\text { Indicam o lugar onde os seres vivos habitam e seus elementos circundantes - bióticos } \\
\text { e abióticos. }\end{array}$ \\
\hline $\begin{array}{l}\text { Comportamentos de conservação } \\
\text { dos recursos }\end{array}$ & Indicam comportamentos necessários à preservação / conservação dos recursos naturais. \\
\hline Efeitos nocivos ao ambiente & Indicam problemas que trazem prejuízos ao ambiente. \\
\hline
\end{tabular}

Fonte: elaborado pelos autores.

Em atenção aos fundamentos éticos e científicos, orientados pelas regulamentações nacionais, todos os participantes e seus responsáveis foram esclarecidos quanto à natureza da pesquisa, seus objetivos, métodos, direitos, riscos e relevância, e sua concordância foi registrada no Termo de Consentimento Livre e Esclarecido (TCLE). Os sujeitos, em consideração ao prescrito foram identificados com denominação $\mathbf{A}$, seguida de um número de ordem $\mathbf{0 1}$, 02, 03, ... 50, a fim de preservar suas identidades.

\section{Resultados e Discussões}

O grupo de alunos do quarto ano era formado por 23 meninas e 27 meninos, que possuíam idades entre 9 e 11 anos, equivalendo à média etária de 9,7 anos. A taxa de distorção idade-série verificada foi de 10\%, valor abaixo da taxa nacional de 19,7\%, registrada em 2018. Esses dados revelam um grupo coeso quanto às expectativas de aprendizagem, visto a pequena quantidade de alunos provenientes de situações que podem indicar reprovação ou abandono escolar, de acordo com as características da trajetória de escolarização expressas pelos órgãos nacionais (INEP, 2018).

As informações acerca do perfil dos alunos, seu cotidiano e sua percepção sobre a escola, coletadas por meio do questionário, revelam que a maioria se considera da cor branca, possui núcleo familiar composto por duas a quatro pessoas (com predominância de convivência com mãe e pai) e religião associada à matriz católica. Quanto ao perfil econômico, a maioria possui acesso a veículo automotor, dispõe de aparelhos televisores e computador com acesso à internet. A maior parte dos alunos declarou que sempre, ou quase sempre, seus pais ou responsáveis vão a reuniões na escola. Prevalentemente, afirmam que seus pais ou responsáveis valorizam e incentivam os estudos, acompanham nas tarefas de casa e conversam sobre o que acontece na escola.

A unidade de ensino na qual foi desenvolvida esta pesquisa está localizada em área urbana e possui dependência administrativa municipal. Dados de infraestrutura do Censo Escolar de 2018 apontam que a escola possui acesso ao saneamento básico, suas dependências são acessíveis aos portadores de deficiência, dispõe de atendimento a alunos com necessidades especiais de aprendizagens, possui biblioteca e sala de informática com acesso à internet de banda larga. Quanto ao rendimento escolar, os anos iniciais apresentam taxa de aprovação equivalente a 98,4\%, sem registros de abandono escolar (INEP, 2018).

Com base nos resultados da Prova Brasil, o Instituto Nacional de Estudos e Pesquisas Educacionais Anísio Teixeira (INEP) destaca que a proporção de $78 \%$ de alunos aprendeu o adequado na competência de leitura e interpretação de textos e $85 \%$ aprendeu o adequado na competência de resolução de problemas até o $5^{\circ}$ ano nessa unidade de ensino 
(INEP, 2018). Esses dados indicam que a proporção de alunos com nível de aprendizado considerado adequado já ultrapassa a meta de 70\% validada para 2022.

\section{O conteúdo cognitivo-estrutural das representações sociais do Meio Ambiente}

Para a estruturação da análise prototípica alguns critérios são fundamentais. $\mathrm{O}$ primeiro refere-se ao valor da frequência de corte (FC), que indica ao software Evocation qual será a menor frequência a ser considerada para a disposição dos termos no quadrante, excluindo os menos citados, por serem pouco significativos; o segundo corresponde ao valor da média geral de ordenamento das evocações (MGOE) das palavras, que é obtido por via da média dos pesos atribuídos às evocações; e o terceiro compreende o valor da frequência mediana (FM), produzido pela apuração da mediana dos valores de frequências, descartadas as frequências abaixo da frequência de corte (VOGEL, 2016; WACHELKE; WOLTER, 2011). Com base nos dados produzidos por um sub-programa do Evocation, obtivemos os seguintes valores: $\mathrm{FC}=2, \mathrm{MGOE}=3,00$ e $\mathrm{FM}=9$.

A administração desses valores junto ao software Evocation nos permitiu a produção do Quadrante de Vergès (Figura 2), com a apresentação dos prováveis elementos que compõem o sistema central (NC) e periférico (Primeira periferia, Zona de contraste e Segunda periferia) da RS do Meio Ambiente. No $1^{\circ}$ quadrante foram listados os termos água, árvores, florestas e lixo no lixo. Segundo as proposições da TNC, a representação está organizada em torno desses elementos, os quais Ihe conferem significação (ABRIC, 1993). Esse conjunto está relacionado à memória coletiva e à história desse grupo de alunos, é estável, coerente e rígido e define sua homogeneidade, uma vez que seus elementos apresentam elevada frequência e relevância no composto de evocações e, por esses motivos, é muito resistente a mudanças (ABRIC, 1993). Esses elementos se articulam aos do sistema periférico, o qual fornece escolta ao conteúdo do NC.

Figura 2 - Quadrante de Vergès para os termos da Representação Social do Meio Ambiente

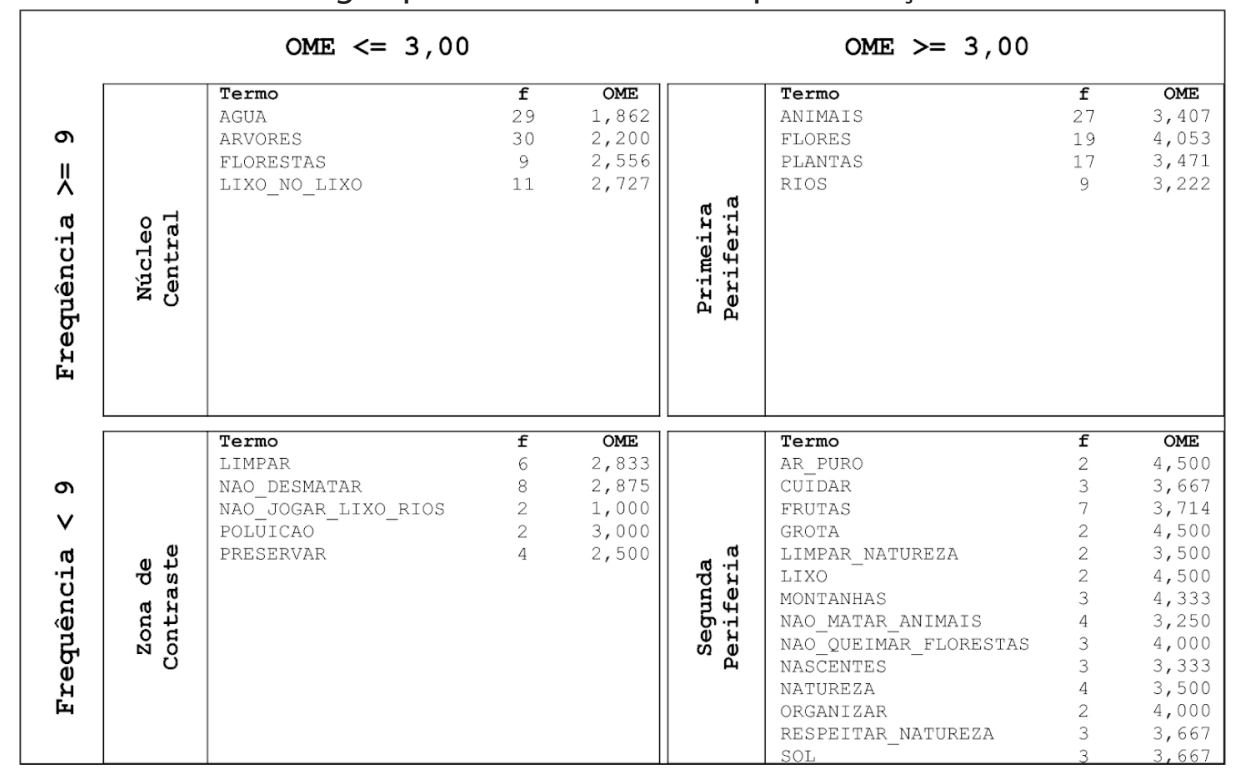

Fonte: elaborado pelos autores.

No $2^{\circ}$ quadrante (Primeira periferia da RS), foram registrados os termos animais, flores, plantas e rios. Esses elementos trazem fortes relações com o sistema central da RS. Possuem 
elevada frequência e ordenamento inferior aos termos do NC. No $3^{\circ}$ quadrante (Zona de contraste da RS), encontramos os termos limpar, não desmatar, não jogar lixo rios, poluição e preservar. Essas palavras foram citadas poucas vezes, porém, atingiram relevância por possuírem alta graduação quanto aos demais termos listados no sistema periférico.

A região mais periférica da RS representada pelo $4^{\circ}$ quadrante, foi composta pelos termos ar puro, cuidar, frutas, grota, limpar natureza, lixo, montanhas, não matar animais, não queimar florestas, nascentes, natureza, organizar, respeitar natureza e sol. Esses elementos foram citados poucas vezes, tendo baixa incidência no pensamento coletivo, indicando uma maior relação com experiências mais individuais dos alunos (ABRIC, 1993).

A produção do gráfico de similitude dos termos da RS de Meio Ambiente teve por interesse a busca de evidências das possíveis relações estabelecidas entre esses elementos da RS. Para a análise de similitude, adotamos, a exemplo do procedimento citado no estudo prototípico, a exclusão dos termos de baixa frequência. Na Figura 3, podemos perceber que o termo água assume centralidade na rede, tendo destaque, também, os termos árvores, animais, flores, plantas, florestas e lixo no lixo. O algoritmo aplicado pelo software Iramuteq detectou a quantidade de ocasiões em que as palavras foram citadas em conjunto, apresentando, nas de maior relevância, um maior número de arestas, representando um alto valor de coocorrências.

Figura 3 - Árvore máxima de similitude para os termos da Representação Social do Meio Ambiente

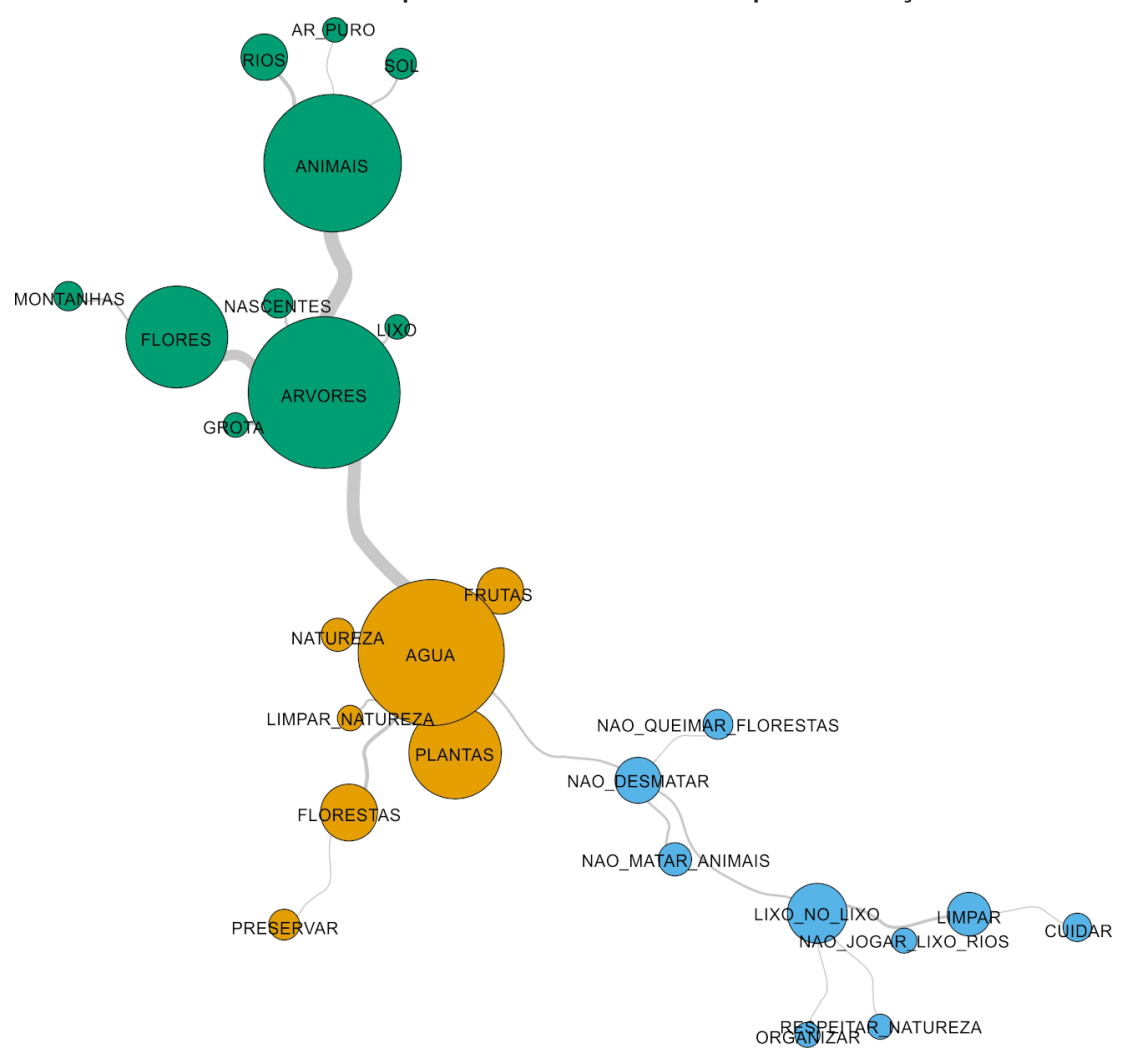

Fonte: elaborado pelos autores.

Podemos, dessa forma, acentuar a evidência de que os termos em questão compõem o NC dessa RS, uma vez que apresentam alto valor simbólico (tratado na relação entre fe OME) e alto poder associativo (tratado na relação entre a quantidade de arestas e coocorrências). 
No interesse de percebermos como os termos da Representação Social de Meio Ambiente se comportam quanto a sua significação, empregamos técnicas de Análise de Conteúdo (BARDIN, 1977). No Quadro 2, foram dispostos os termos da RS, conforme sua estruturação e categorização.

Quadro 2 - Categorização dos termos da Representação Social do Meio Ambiente

\begin{tabular}{|c|c|c|c|c|}
\hline \multirow[b]{2}{*}{ Categorias } & \multicolumn{4}{|c|}{ Elementos estruturais da Representação Social do Meio Ambiente } \\
\hline & Núcleo central & Primeira periferia & Zona de contraste & Segunda periferia \\
\hline $\begin{array}{l}\text { Espaço, elementos } \\
\text { bióticos e abióticos }\end{array}$ & $\begin{array}{l}\text { Água } \\
\text { Árvores } \\
\text { Florestas }\end{array}$ & $\begin{array}{l}\text { Animais } \\
\text { Flores } \\
\text { Plantas } \\
\text { Rios }\end{array}$ & - & $\begin{array}{l}\text { Ar_puro } \\
\text { Frutas } \\
\text { Grota } \\
\text { Montanhas } \\
\text { Nascentes } \\
\text { Natureza }\end{array}$ \\
\hline $\begin{array}{l}\text { Comportamentos } \\
\text { de conservação dos } \\
\text { recursos }\end{array}$ & Lixo_no_lixo & - & $\begin{array}{l}\text { Limpar } \\
\text { Nao_desmatar } \\
\text { Nao_jogar_lixo_rios } \\
\text { Preservar }\end{array}$ & $\begin{array}{l}\text { Cuidar } \\
\text { Limpar_natureza } \\
\text { Nao_matar_animais } \\
\text { Nao_queimar_florestas }\end{array}$ \\
\hline $\begin{array}{l}\text { Efeitos nocivos ao } \\
\text { ambiente }\end{array}$ & - & - & Poluição & Lixo \\
\hline
\end{tabular}

Fonte: elaborado pelos autores.

Diante da categorização apresentada, é possível sinalizar que a representação de Meio Ambiente dos alunos em questão se caracteriza, de modo mais amplo, como naturalista (ABÍLIO etal., 2005;CARVALHO, 2012;FONSECA; OLIVEIRA, 2011;NASCIMENTO-SCHÜLZE, 2000; REIGOTA, 1997; SAUVÉ, 2003). Ou seja, para o grupo discente, a definição de Meio Ambiente se aproxima do conceito de natureza, apresentando-o como um espaço com seus elementos bióticos e abióticos onde os seres vivos habitam. Nesse caso, como aponta Reigota (1997), esses elementos representam o que alguns autores denominam como "primeira natureza" ou "natureza intocada". O NC se caracteriza fortemente sob esses aspectos, trazendo, ainda, um elemento que carrega relação com comportamentos de conservação do ambiente. Para Fonseca e Oliveira (2011), essas atividades, que objetivam a adoção de comportamentos de conservação e de habilidades para a gestão ambiental, correspondem ao pensamento denominado conservacionista.

A segunda periferia é unicamente marcada pelo pensamento naturalista, seguida pela zona de contraste, em que figuram basicamente elementos conservacionistas. Neste quadrante, surge uma referência a ações de efeito nocivo ao ambiente (SAUVÉ, 2003). A região mais periférica da $\mathrm{RS}$, que abriga elementos que refletem experiências mais individuais do grupo, traz uma caracterização intermediada pelo pensamento naturalista e conservacionista, também com uma referência a problemas ambientais. Segundo Fonseca e Oliveira (2011, p. 236),

A junção das características das correntes naturalista e conservacionista pode ser traduzida em atividades que apontam para uma tendência afetiva, comportamentalista e tecnicista, voltadas tanto para o cuidado com a natureza, como para a resolução de problemas ambientais, ambos apresentados considerando apenas os aspectos naturalísticos. Assim, as atividades marcam um forte tom de denúncia, porém sem se preocupar com as interfaces (culturais, sociais, econômicas, políticas etc.) que permeiam a relação entre o homem e a natureza. 
Às características naturalistas e conservacionistas das RS dos alunos podemos acrescentar a presença de uma visão antropocêntrica utilitarista do meio ambiente (ABÍLIO et al., 2005), a exemplo dos discursos produzidos por A4, ao justificar a escolha do termo água como o mais importante em sua lista, afirmando que "a água é muito importante, pois sem ela nós morreremos", e de A12, ao apresentar o termo "árvores" como mais significativo, dizendo: "eu acho as árvores mais importantes porque elas limpam o ar, fazem sombras e frutos".

Apesar da visão antropocêntrica e de termos relacionados a problemas ambientais causados pela ação humana terem sido citados pelos alunos, o termo "ser humano/homem" não foi mencionado entre os respondentes. Podemos, assim, denotar que o ser humano não faz parte da RS de meio ambiente dos alunos. É como se o ser humano fosse um agente externo, sendo percebidas apenas suas ações prejudiciais.

Nesses termos, podemos sinalizar, como hipótese para futuras investigações com atenção voltada à dinâmica dos fatores psicossociais envolvidos na estruturação da RS em questão, que esses elementos que caracterizam uma visão naturalista, conservacionista e antropocêntrico utilitarista estão, possivelmente, ancorados nos modelos de Educação Ambiental Tradicional, presentes nos espaços escolares. Nascimento-Schülze (2000), ao citar os resultados dos trabalhos de alguns pesquisadores, destaca a presença significativa de representações desse calibre em grupos de professores e, também, em livros didáticos que abordavam o tema meio ambiente.

A esse fato, acrescentamos a dissonância entre as propostas governamentais e as práticas educacionais, que, enquanto condutas sociais, são orientadas pelas RS desses grupos. De modo geral, os programas de governo voltados à educação ambiental abrangem:

(I) uma preocupação com uma superação da visão fragmentada de mundo; (II) a necessidade de reintegrar os seres humanos ao seu ambiente e (III) a preocupação com o desenvolvimento sustentável, buscando garantir as necessidades das gerações atuais, sem comprometer as futuras (NASCIMENTO-SHÜLZE, 2000, p. 72).

De modo consoante a Sauvé (2003), para além de uma definição de meio ambiente, o que se pretende por vias da Educação Ambiental Crítica é considerar as diferentes representações, sejam elas como "naturais" (elementos primários que devem ser preservados e admirados), como "conservacionistas" (fonte de recursos que devem ser administrados), como "problemas" (que afetam o ambiente e devem ser prevenidos), dentre outras, no sentido de promover uma visão articulada de caráter globalizante, em que o meio é integrado pelo ambiente e pela sociedade (REIGOTA, 1997).

A ideia de caráter globalizante está associada ao que Carvalho $(2012$, p. 37) denomina de visão socioambiental, orientada por uma racionalidade complexa e interdisciplinar que permite pensar o meio ambiente para além da primeira natureza, entendendo-o como um "[...] campo de interações entre a cultura, a sociedade e a base física e biológica dos processos vitais, no qual todos os termos dessa relação se modificam dinamicamente e mutuamente".

Nesses termos, podemos sugerir que, mesmo havendo interlocuções entre as caracterizações das RS do Meio Ambiente dos alunos, um trabalho de educação ambiental cerceado a apenas uma dessas seria ambíguo e promoveria uma visão restrita das complexas relações entre meio ambiente e sociedade. 


\section{Considerações Finais}

Conhecer o conteúdo representacional, na perspectiva que nos propomos neste trabalho, nos parece de fundamental importância para a organização de ações pautadas nos fundamentos da Educação Ambiental Crítica. Consideramos, no entanto, que o tema Meio Ambiente é amplamente tratado nos meios sociais e, por isso, podemos entendê-lo um "assunto" em constante elaboração, o que pode configurar a mobilidade do conteúdo representacional nos diferentes grupos sociais.

Assim, o presente trabalho pretende contribuir nas discussões acerca da importância de se conhecer como é representado o objeto Meio Ambiente por determinados grupos. Nessa direção de investigação, se deseja implementar práticas voltadas à Educação Ambiental, no interesse de legitimar recursos que permitam abordagens tangentes a uma visão socioambiental, relacionada à formação de indivíduos à vida social, cultural e natural. Sem esses esforços investigativos, é possível que se incorra em tentativas frustradas, ampliando o abismo entre propostas didáticas e finalidades educacionais críticas.

Sinalizamos, ainda, que, na formação de cidadãos críticos, deposita-se uma expectativa de um movimento coletivo que gere mobilização e transformação para a construção de uma nova sociedade. Este movimento é de responsabilidade de todos: escola, mídia, família, enfim, da sociedade em geral. Acrescentamos que o trabalho com a perspectiva da Educação Ambiental Crítica exige muito mais que ações isoladas, devendo-se pautar na reestruturação das práticas de modo a confrontar os processos tradicionais da Educação Ambiental.

\section{Agradecimentos}

O presente trabalho foi realizado com apoio da Coordenação de Aperfeiçoamento de Pessoal de Nível Superior (CAPES) e da Prefeitura Municipal de Castelo, ES.

\section{Referências}

ABÍLIO, F. J. P. et al. Meio Ambiente e educação ambiental: uma análise crítica dos livros didáticos de ciências de ensino fundamental publicados no período de 1990 a 2004. In: ABÍLIO, F. J. P.; GUERRA, R. A. T. (org.). A questão ambiental no ensino de ciências e a formação continuada de professores de ensino fundamental. João Pessoa: UFPB, 2005. p. 63-78.

ABRIC, J. C. A abordagem estrutural das representações sociais. In: MOREIRA, A. S. P.; OLIVEIRA, C. P. (org.). Estudos interdisciplinares de representação social. Goiânia: AB, 1998. p. 27-38.

ABRIC, J. C. Central system, peripheral system: their functions and roles in the dynamics of social representations. Papers on Social Representations, Lisboa, v. 2, n. 2, p. 75-78, 1993. Disponível em: http://psr.iscte-iul.pt/index.php/PSR/article/view/126/90. Acesso em: 18 set. 2020.

ALVES-MAZZOTTI, A. J. Representações sociais: aspectos teóricos e aplicações à educação. Múltiplas Leituras, São Paulo, v. 1, n. 1, p. 18-43, 2008. DOI: https://doi.org/10.15603/1982-8993/ ml.v1n1p18-43.

BARDIN, L. Análise de conteúdo. Lisboa: Edições 70, 1977.

BOMFIM, A. M; PICCOLO, F. D. Educação ambiental crítica: a questão ambiental entre os conceitos de cultura e trabalho. REMEA, Rio Grande, v. 27, p. 184-195, 2011. Disponível em: https://periodicos. furg.br/remea/article/view/3236/1923. Acesso em: 18 set. 2020. 
BRASIL. Lei n. 9.795, de 27 de abril de 1999. Dispõe sobre a educação ambiental, institui a política nacional de educação ambiental e dá outras providências. Diário Oficial [da República Federativa do Brasil], Brasília, 28 abr.1999. Disponível em: http://www.planalto.gov.br/ccivil_03/leis/l9795.htm. Acesso em: 18 set. 2020.

BRASIL. Ministério da Educação. Base nacional comum curricular: versão final. Brasília: MEC, 2018. Disponível em: https://cutt.ly/KfXFMIZ. Acesso em: 18 set. 2020.

BRASIL. Ministério da Educação. Parâmetros curriculares nacionais: terceiro e quarto ciclos do ensino fundamental: introdução aos parâmetros curriculares nacionais. Brasília: MEC, 1998.

BRASIL. Ministério da Educação. Conselho Nacional de Educação. Parecer CNE/CP n 14/2012. Diário Oficial da União: seção 1, Brasília, p. 18, 15 jun. 2012a. Disponível em: https://cutt.ly/YfXF9ZB. Acesso em: 18 set. 2020.

BRASIL. Ministério da Educação. Conselho Nacional de Educação. Resolução n. 2, de 15 de junho de 2012. Estabelece as diretrizes curriculares nacionais para a educação ambiental. Diário Oficial da União: seção 1, Brasília, p. 70, 18 jun. 2012b. Disponível em: https://cutt.ly/hfXF7Fo. Acesso em: 18 set. 2020.

BRASIL. Ministério do Meio Ambiente. Política de educação ambiental: documentos, histórico nacional e mundial, gestão e programa nacional de educação ambiental. Brasília: MMA, [2020]. Disponível em: https://cutt.ly/GfXGqOu. Acesso em: 18 set. 2020.

CAMPOS, P. H. F. O estudo da ancoragem das representações sociais e o campo da educação. Revista de Educação Pública, Cuiabá, v. 26, n. 63, p. 775-797, 2017. Disponível em: https://cutt.ly/4fXGrsj. Acesso em: 18 set. 2020.

CARSON, R. Silent spring. Boston: Houghton Mifflin, 1962.

CARVALHO, I. C. M. Educação ambiental: a formação do sujeito ecológico. 6. ed. São Paulo: Cortez, 2012.

CAVALCANTI NETO, A. L. G. C.; AMARAL, E. M. R. Ensino de ciências e educação ambiental no nível fundamental: análise de algumas estratégias didáticas. Ciência \& Educação, Bauru, v. 17, n. 1, p. 129144, 2011. DOI: https://doi.org/c33sf8.

CHAIB, M. Representações sociais, subjetividade e aprendizagem. Cadernos de Pesquisa, São Paulo, v. 45, n. 156, p. 358-372, 2015. DOI: https://doi.org/10.1590/198053143201.

DUVEEN, G. Introdução. In: MOSCOVICI, S. Representações sociais: investigações em psicologia social. 5. ed. Petrópolis: Vozes, 2007. p. 7-28.

FONSECA, F. S. R.; OLIVEIRA, L. G. Concepções de meio ambiente dos educadores ambientais do zoológico de Goiânia: implicações nas atividades e contribuições para a formação do sujeito ecológico? Educar em Revista, Curitiba, n. 41, p. 231-246, 2011. DOl: https://doi.org/d9rh.

FRANCO, M. L. P. B. Análise de conteúdo. 2. ed. Brasília: Liber, 2005.

GILLY, M. As representações sociais no campo educativo. Educar em Revista, Curitiba, n. 19, p. 231 252, 2002. DOI: http://dx.doi.org/10.1590/0104-4060.257.

GUIMARÃES, M. Educação ambiental crítica. In: LAYRARGUES, P. P. (org.). Identidades da educação ambiental brasileira. Brasília: Ministério do Meio Ambiente, 2004. p. 25-34.

INEP. Indicadores educacionais. Brasília: INEP, [2018]. Disponível em: http://portal.inep.gov.br/ indicadores-educacionais. Acesso em: 18 set. 2020.

JOVCHELOVITCH, S. Psicologia social, saber, comunidade e cultura. Psicologia \& Sociedade, São Paulo, n. 16, p. 20-31, 2004. Disponível em: https://cutt.ly/VfXGXQE. Acesso em: 18 set. 2020. 
LOUREIRO, C. F. B.; TREIN, E.; TOZONI-REIS, M. F. C.; NOVICKI, V. Contribuições da teoria marxista para a educação ambiental crítica. Cadernos Cedes, Campinas, v. 29, n. 77, p. 81-97, 2009. DOI: https://doi. org/d9zgbg.

MEADOWS, D. H.; MEADOWS, D.; RANDERS, J.; BEHRENS III, W. W. The limits to growth. New York: Universe Books, 1972.

MOSCOVICI, S. A psicanálise, sua imagem e seu público. Petrópolis: Vozes, 2012.

NASCIMENTO-SCHÜLZE, C. M. Representações sociais da natureza e do meio ambiente. Revista de Ciências Humanas, Florianópolis, ed. esp., p. 67-81, 2000. Disponível em: https://cutt.ly/5fXGEE1. Acesso em: 18 set. 2020.

ORNELLAS, M. L. S. Educação, afeto e representação social. In: NASCIMENTO, A. D.; HETKOWSKI, T. M. (org.). Educação e contemporaneidade: pesquisas científicas e tecnológicas. Salvador: EDUFBA, 2009. p. 275-293.

POZO, J. I.; CRESPO, M. A. G. A aprendizagem e o ensino de ciências: do conhecimento cotidiano ao conhecimento científico. 5. ed. Porto Alegre: Artmed, 2009.

REIGOTA, M. Meio ambiente e representação social. 2. ed. São Paulo: Cortez, 1997.

ROSA, R. S.; SANTOS, K. A representação social de meio ambiente como ponto de partida para ações de educação ambiental: uma ocupação irregular como espaço de educação não escolar. Ambiente \& Educação, Rio Grande, v. 22, n. 1, p. 183-197, 2017. Disponível em: https://cutt.ly/PfXGFD3. Acesso em: 18 set. 2020.

SÁ, C. P.; ARRUDA, A. O estudo das representações sociais no Brasil. Revista de Ciências Humanas, Florianópolis, ed. esp., p. 11-31, 2000. Disponível em: https://periodicos.ufsc.br/index.php/ revistacfh/article/download/24121/21516. Acesso em: 18 set. 2020.

SÁ, C. P. Núcleo central das representações sociais. Petrópolis: Vozes, 1996.

SAUVÉ. L. Perspectivas curriculares para la formación de formadores en educación ambiental. In: FORO NACIONAL SOBRE LA INCORPORACIÓN DE LA PERSPECTIVA AMBIENTAL EM LA FORMACIÓN TÉCNICA Y PROFESIONAL, 1., 2003, San Luis Potosi. Memorias [...]. San Luis Potosi, 2003. Disponível em: https://cutt.ly/QfXGX9I. Acesso em: 18 set. 2020.

SCHÜNEMANN, D. R.; ROSA, M. B. Conscientização ambiental na educação infantil. Ambiente \& Educação, Rio Grande, v. 18, n. 1, p. 122-132, 2010. Disponível em: https://periodicos.ufsm.br/remoa/ article/view/2295. Acesso em: 18 set. 2020.

SILVA, A. M. T. B.; MAZZOTTI, T. B. A física pelos professores de física: a contribuição da teoria das representações sociais. Ciência \& Educação, Bauru, v. 15, n. 3, p. 515-528, 2009. DOI: https://doi.org/ ds9qq4.

VERGÈS, P. L'analyse des représentations sociales par questionnaires. Revue Française de Sociologie, Paris, v. 42, n. 3, p. 537-561, 2001. Disponível em: https://cutt.ly/yfXG0D4. Acesso em: 18 set. 2020.

VITTORAZZI, D. L. A ciência, seu ensino e suas representações: implicações na construção do conhecimento científico no ensino fundamental. 2018. 171 f. Dissertação (Mestrado em Ciência, Tecnologia e Educação) - Centro Federal de Educação Tecnológica Celso Suckow da Fonseca, Rio de Janeiro, 2018.

VOGEL, M. Influências do PIBID na representação social de licenciandos em química sobre ser "professor de química". 2016. 201 f. Tese (Doutorado em Ensino de Ciências) - Universidade de São Paulo, São Paulo, 2016.

WACHELKE, J.; WOLTER, R. Critérios de construção e relato da análise prototípica para representações sociais. Psicologia: teoria e pesquisa, Brasília, v. 27, n. 4, p. 521-526, 2011. DOI: https://doi.org/10.1590/S0102-37722011000400017. 